\title{
Atividade fotossintética da beterraba submetidas a adubação mineral e esterco bovino
}

\section{Photosynthetic activity beet submitted mineral fertilizer and manure}

\author{
Ancélio Ricardo de Oliveira Gondim ${ }^{1}$, José Lucas Guilherme Santos ${ }^{2}$, Renato de Pereira Lira ${ }^{3}$, Marcos Eric Barbosa Brito ${ }^{4}$, \\ Francisco Hevilásio Freire Pereira
}

\begin{abstract}
RESUMO - O presente trabalho foi desenvolvido com o objetivo avaliar os efeitos da adubação mineral e esterco bovino sobre as trocas gasosas em plantas de beterraba. O experimento foi conduzido em condições de campo, com delineamento em blocos casualizados, no esquema fatorial $5 \times 2$, com três repetições. Os tratamentos serão constituídos por cinco doses de esterco bovino $\left(2,0 ; 4,0 ; 6,0 ; 8,0 ; \mathrm{e} 10,0 \mathrm{~kg} \mathrm{~m}^{-2}\right)$, na presença e ausência de adubo mineral. Foram avaliados os seguintes parâmetros: fotossíntese liquida (A), a condutância estomática (gs), a transpiração (E) e a concentração intercelular de $\mathrm{CO}_{2}(\mathrm{Ci})$, eficiência instantânea do uso da água $(\mathrm{A} / \mathrm{E})$, eficiência de carboxilação $(\mathrm{A} / \mathrm{Ci})$. As plantas de beterraba cultivadas na presença da adubação mineral e com a maior dose de esterco revelaram valores maiores para condutância estomática. $\mathrm{O}$ tratamento de 10,0 $\mathrm{kg} \mathrm{m}^{-2}$ de esterco apresentou maior taxa de fotossíntese. Os valores de transpiração e concentração intercelular de $\mathrm{CO}_{2}$ na beterraba foram influenciados pelas doses de esterco.
\end{abstract}

Palavras-chaves - Trocas gasosas; Beta vulgaris L.; esterco bovino

ABSTRACT - This study was developed to evaluate the effects of mineral fertilizers and cattle manure on gas exchange in beet plants. The experiment was conducted under field conditions, a randomized block design, in factorial scheme $5 \times 2$, with three replications. The treatments will consist of five doses of cattle manure $\left(2.0,4.0,6.0,8.0\right.$, and $\left.10.0 \mathrm{~kg} \mathrm{~m}^{-2}\right)$ in the presence and absence of mineral fertilizer. We evaluated the following parameters: net photosynthesis (A), stomatal conductance (gs), transpiration $(\mathrm{E})$ and intercellular $\mathrm{CO}_{2}$ concentration $(\mathrm{Ci})$, instantaneous efficiency of water use $(\mathrm{A} / \mathrm{E})$, carboxylation efficiency ( A / C). Beet plants grown in the presence of mineral fertilization and the greatest amount of manure showed higher values for stomatal conductance. Treatment of $10.0 \mathrm{~kg} \mathrm{~m}^{-2}$ manure showed higher rate of photosynthesis. The values of transpiration and intercellular $\mathrm{CO}_{2}$ concentration in beets were influenced by doses of manure.

Key words - Gas exchange; Beta vulgaris L.; manure

\footnotetext{
*Autor para correspondência

Recebido para publicação em 10/03/2015; aprovado em 25/05/2015

${ }^{1}$ D. Sc.,., Universidade Federal de Campina Grande - CCTA, Pombal; (083) 3431-4000,ramal 4048, anceliogondim@hotmail.com.

${ }^{2}$ Graduando em agronomia, Universidade Federal de Campina Grande - CCTA, Pombal, E-mail

${ }^{3}$ Graduando em agronomia, Universidade Federal de Campina Grande - CCTA, Pombal, E-mail

${ }^{4}$ D. Sc., Universidade Federal de Campina Grande - CCTA, Pombal; marcosericbb@yahoo.com.br

${ }^{5}$ D. Sc., Universidade Federal de Campina Grande - CCTA, Pombal, E-mail fhfp@ hotmail.com
} 


\section{INTRODUÇÃO}

A beterraba (Beta vulgaris L.) pertence à família Quenopodiaceae. É uma das hortaliças mais importante do mundo, depois da batata, tomate, cebola, alho, pimentão, repolho e cenoura; devido à sua adaptação em regiões de clima semiárido, vem-se observando, nos últimos dez anos, aumento da demanda dessa hortaliça, para consumo "in natura" e também para as indústrias de conservas. A cultura é bastante exigente em termos nutricionais, requerendo um programa de adubação equilibrado capaz de repor os nutrientes extraídos pela cultura, evitando assim o esgotamento do solo. Porém, adubações excessivas contendo $\mathrm{N}$ podem afetar na qualidade da raiz, provocando o acúmulo de glutamina (SOUZA et al., 2003). Aliado a isso, existe uma grande necessidade da cultura pela adubação orgânica, fazendo com que essa hortaliça seja um importante componente no enfoque holístico da agricultura orgânica (VILAS BÔAS et al., 2004).

Atualmente, adubos orgânicos de várias origens são empregados no cultivo dessa hortaliça, destacando-se o esterco, que, além de proporcionar melhoria das propriedades físicas e químicas do solo, reduz a necessidade de uso de adubos minerais, além de aumentar sua produtividade (SILVA et al., 2010).

Em estudo de nutrição em plantas, a fotossíntese tem recebido especial atenção por ser a principal fonte de carbono orgânico, de energia para o crescimento e produção de biomassa das plantas (LAWLOR, 2002). Larcher (2004) afirma que a influência do estado nutricional da planta sobre a fotossíntese ocorre de muitas maneiras, sendo que quase sempre maiores taxas fotossintéticas são alcançadas por meio da adubação. Segundo Costa et al., (2001) mudanças na absorção de nutrientes levam a alterações da fisiologia das plantas, dentre outros fatores, à abertura estomática e ao aumento ou diminuição da área foliar, estando esses fatores intimamente ligados com a eficiência fotossintética.

Vários estudos com hortaliças demonstram correlações positivas entre tratamentos com adubação e trocas gasosas, como os observados em berinjela (BRANDÃO FILHO et al., 2003), couve e pimentão (VILANOVA e SILVA JUNIOR, 2010), porém, estudos discutindo como esses padrões ocorrem em beterraba ainda são escassos.

Existe, atualmente, um número restrito de referências sobre a relação de adubação, aliada aos efeitos na atividade fotossintética em hortaliças. Poucos relatos foram encontrados na literatura referente a resposta fotossintetizante de beterraba. Estudos desta natureza, porém, são fundamentais para compreender os processos do potencial fotossintético da beterraba e suas relações com o ambiente em que estão se desenvolvendo, permitindo assim a ampliação dos conhecimentos sobre sua adaptabilidade às condições de cultivo. Dentro desse contexto, o presente trabalho teve por finalidade avaliar os efeitos de doses de esterco na presença e ausência da adubação mineral, nas trocas gasosas em plantas de beterraba.

\section{MATERIAL E MÉTODOS}

O experimento foi conduzido no campus de Pombal do CCTA da Universidade Federal de Campina Grande (UFCG), Pombal - PB, no período de 02/12/2013 a 20/02/2014. A cidade de Pombal situa-se no semiárido do nordeste brasileiro, segundo a classificação de Köppen, o município tipo de clima: BSw'h', clima quente e semiárido, caracterizado pela insuficiência das chuvas, com precipitação pluvial média anual de $700 \mathrm{~mm}$ e temperaturas elevadas acarretando forte evaporação, apresentando temperatura média anual de $30,5^{\circ} \mathrm{C}$ e tendo apenas duas estações climáticas bem definidas durante o ano, uma chuvosa e outra seca.

Utilizou-se a cultivar de beterraba "cv. Katrina", pertencente ao grupo Wonder. O cultivo foi realizado em canteiros de $15 \mathrm{~cm}$ de altura, com $1 \mathrm{~m}$ de largura, contendo quatro fileiras transversais distanciadas de $25 \mathrm{~cm}$ e de $10 \mathrm{~cm}$ entre plantas. $\mathrm{O}$ solo utilizado foi classificado como Neossolo flúvico, textura areia franca (areia grossa $=801$; silte $=143 \mathrm{e}$ argila $=56 \mathrm{~g} \mathrm{~kg}^{-1}$ ), cujos resultados médios das análises químicas, antes da instalação do experimento, foram: $\mathrm{pH}$ em $\mathrm{CaCl}_{2}=7,4 ; \mathrm{P}=163 \mathrm{mg} \mathrm{dm}^{-3} ; \mathrm{K}=0,40 ; \mathrm{Na}=0,22 ; \mathrm{Ca}=6,3$; $\mathrm{Mg}=5,6 ; \mathrm{Al}=0,0 ; \mathrm{H}+\mathrm{Al}=0,0 ; \mathrm{SB}=14,2$ e $\mathrm{CTC}=14,2$ $\mathrm{cmol}_{\mathrm{c}} \mathrm{dm}^{-3} ; \mathrm{MO}=3,00 \mathrm{~g} \mathrm{~kg}^{-1}$.

Os tratamentos foram constituídos por cinco doses de esterco bovino $\left(2,0 ; 4,0 ; 6,0 ; 8,0 ; \mathrm{e} 10,0 \mathrm{~kg} \mathrm{~m}^{-2}\right)$, na presença e ausência de adubo mineral. Os estercos foram previamente curtidos durante 30 dias.

$\mathrm{O}$ delineamento experimental utilizado foi o blocos casualizados, no esquema fatorial $5 \times 2$, com três repetições. A parcela experimental consistiu de um canteiro com $1 \mathrm{~m}$ comprimento; considerando como útil a área compreendida pelas duas fileiras centrais do canteiro, excetuando-se as plantas das extremidades. As plantas foram dispostas no espaçamento de $0,15 \times 0,2 \mathrm{~m}$.

A semeadura foi realizada em 02/12/2014 diretamente no solo, a uma profundidade aproximada de $1,0 \mathrm{~cm}$, colocando-se três sementes por cova. A emergência, acima de $80 \%$ das plantas, foi observada cinco dias após da semeadura. Dez dias após a emergência realizou-se o desbaste deixandose apenas uma planta por cova. A adubação mineral de plantio foi realizada aos cinco dias antes do plantio. Esta adubação consistiu da aplicação de $36 \mathrm{~g} \mathrm{~m}^{-2}$ de $\mathrm{P}_{2} \mathrm{O}_{5}$ e de 18,0 $\mathrm{g} \mathrm{m}^{-2}$ de $\mathrm{K}_{2} \mathrm{O}$ e de $14 \mathrm{~g} \mathrm{~m}^{-2}$ de $\mathrm{N}$, parcelando igualmente na adubação de cobertura, aos 15,30 e 45 dias após a emergência (RAIJ, et al. 1997). As irrigações foram efetuadas por um sistema de micro-aspersão, com turno de rega diária parcelada em duas aplicações (manhã e tarde), fornecendo-se uma lâmina de água de aproximadamente $8 \mathrm{~mm} \mathrm{dia}^{-1}$. Capinas manuais foram realizadas sempre que necessárias.

As trocas gasosas foram avaliadas aos 60 dias após o plantio (DAP) da beterraba. Nesta ocasião foram determinadas a fotossíntese liquida (A), a condutância estomática (gs), a transpiração (E) e a concentração intercelular de $\mathrm{CO}_{2}(\mathrm{Ci})$, medidos com analisador de gás no infravermelho (IRGA) LCpro+ (Analytical Development, Kings Lynn, UK) com fonte de luz constante de $1.200 \mu \mathrm{mol}$ de fótons $\mathrm{m}^{-2} \mathrm{~s}^{-1}$.

Os dados foram submetidos a análise de variância com comparações de médias pelo Teste Tukey a 5\% de probabilidade.

\section{RESULTADOS}

Verificou-se efeito significativo para todas as características analisadas em relação aos tratamentos utilizados. 
Apesar da fotossíntese líquida e a concentração intercelular de $\mathrm{CO}_{2}$ não apresentarem diferença significativa na presença e ausência da adubação mineral, verificou-se que a presença da adubação mineral foi superior em relação a ausência da adubação mineral (Tabela 1).
A transpiração e a concentração intercelular de $\mathrm{CO}_{2}$ não apresentaram variações significativas independentemente das doses de esterco utilizadas, isso se deve ao fato de que quanto menos a fotossíntese liquida, maior foi a concentração intercelular de $\mathrm{CO}_{2}$. (Figura 1).

Tabela 1 - Fotossíntese líquida (A), transpiração (E), condutância estomática (Gs) e concentração intercelular de $\mathrm{CO}_{2}$ (Ci) em plantas de beterraba cultivadas com e sem adubo mineral. UFCG, Pombal, 2014.

\begin{tabular}{ccccc}
\hline \hline Adubação mineral & $\begin{array}{c}\mathrm{A} \\
\left(\mu \mathrm{mol} \mathrm{m} \mathrm{s}^{-1}\right)\end{array}$ & $\begin{array}{c}\mathrm{E} \\
\left(\mathrm{mmol} \mathrm{m}^{-2} \mathrm{~s}^{-1}\right)\end{array}$ & $\begin{array}{c}\mathrm{Gs} \\
\left(\mathrm{mmol} \mathrm{m}^{-2} \mathrm{~s}^{-1}\right)\end{array}$ & $\begin{array}{c}\mathrm{Ci} \\
\left(\mathrm{mg} \mathrm{L}^{-1}\right)\end{array}$ \\
\hline Presença & $14,01 \mathrm{a}$ & $4,30 \mathrm{a}$ & $0,44 \mathrm{a}$ & $219,07 \mathrm{a}$ \\
Ausência & $12,41 \mathrm{a}$ & $3,77 \mathrm{~b}$ & $0,32 \mathrm{~b}$ & $211,43 \mathrm{a}$ \\
\hline DMS & 1,61 & 0,40 & 0,021 & 8,15 \\
\hline \hline
\end{tabular}

Médias com letras diferentes diferem entre si pelo teste de Tukey a 5\% de probabilidade.

A superioridade na condutância estomática na presença da adubação mineral em relação a ausência deveu-se possivelmente de que o potássio presente na adubação pode ter aumentado a condutância estomática (Figura 1C). De acordo com Catuchi et al. (2012), a adubação potássica aumentou a condutância estomática em soja, pelo fato de que o K pode conferir uma dinâmica adequada da condutância estomática às plantas, além de ser um elemento extremamente importante na ativação da função carboxilase da Rubisco, o que contribui para uma maior atividade fotossintética (CAKMAK, 2005; PRADO, 2008). Ainda Epstein e Bloom (2006) relata que o potássio é um dos nutrientes importantes para planta, pois participa de processos como abertura e fechamento dos estômatos, fotossíntese, transporte de carboidratos e respiração. Além do mais a regulação eficaz da abertura estomática é fundamental para que as plantas possam ter um bom desenvolvimento.
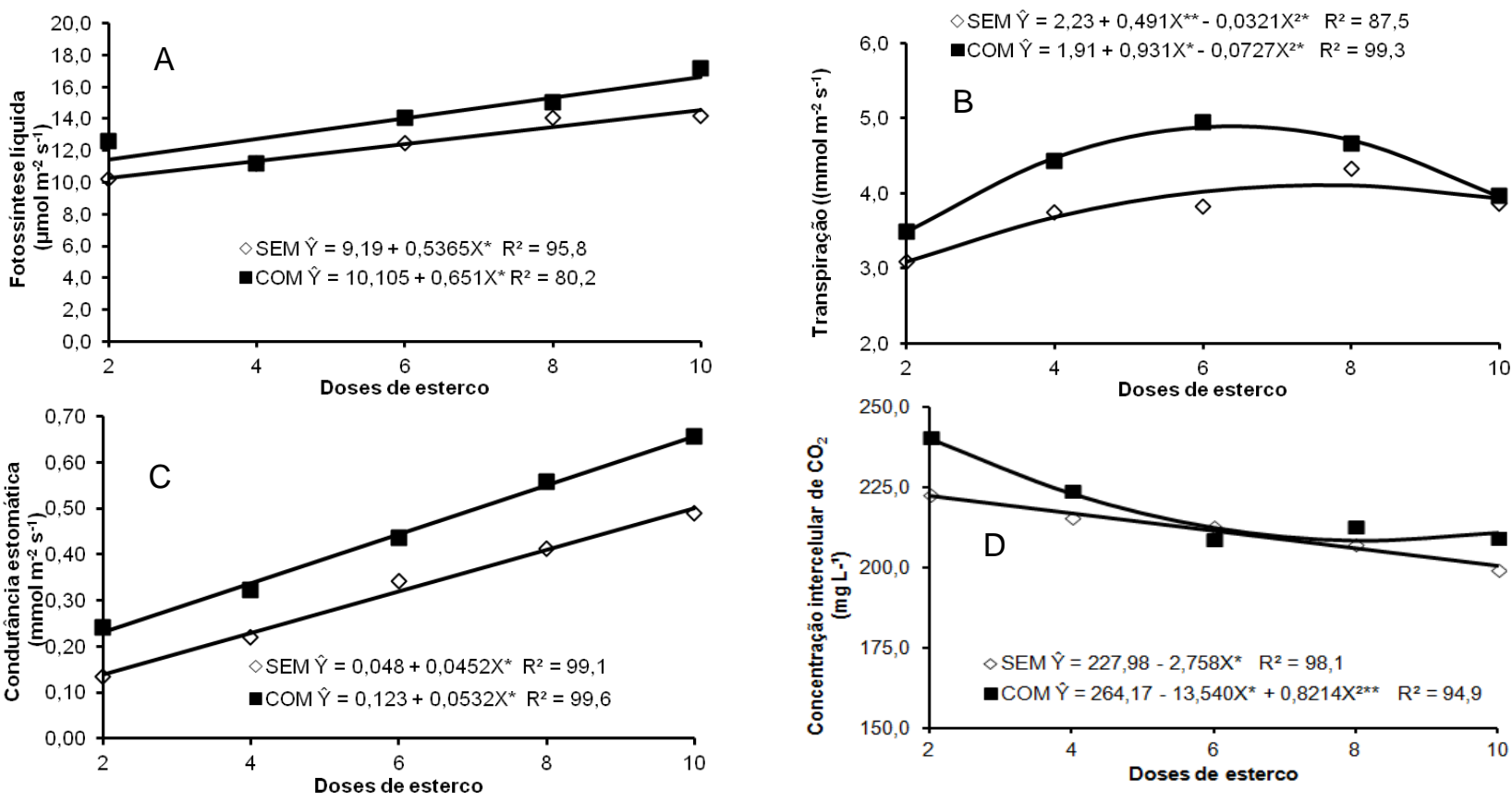

Figura 1. Fotossíntese líquida, transpiração, condutância estomática e concentração intercelular de $\mathrm{CO}_{2}$ em plantas de beterraba submetidas a doses de esterco na presença e ausência da adubação mineral. UFCG, Pombal, 2014.

A fotossíntese líquida apresentou um comportamento linear no qual verificou-se máximo acúmulo de $15,6 \mu \mathrm{mol} \mathrm{m} \mathrm{m}^{-2}$ $\mathrm{s}^{-1}$ na dose de $10 \mathrm{~kg}$ de esterco (Figura 2A). Esses resultados demonstram que a dose de esterco é importante no incremento da fotossíntese líquida. Isso ocorre possivelmente devido o esterco proporcionar, além de melhorias na fertilidade do solo, favorece também melhorias nas características físicas e biológicas do solo. Sendo assim, esses resultados reforçam a importância da adubação com esterco em cultivos agrícolas, principalmente, em espécies olerícolas.
A condutância estomática apresentou um comportamento linear no qual verificou-se máximo acúmulo de $0,58 \mathrm{mmol} \mathrm{m}^{-2} \mathrm{~s}^{-1}$ na dose de $10 \mathrm{~kg}$ de esterco independentemente da adubação mineral (Figura 2C). Esses resultados demonstram que a dose de esterco é importante no incremento da condutância estomática. Isso ocorre possivelmente devido o esterco proporcionar, além de melhorias na fertilidade do solo, favorece também melhorias nas características físicas e biológicas do solo. Sendo assim, esses resultados reforçam a importância da adubação com 
esterco em cultivos agrícolas, principalmente, em espécies olerícolas.

A concentração intracelular de $\mathrm{CO}_{2}$ apresentou um comportamento quadrático no qual verificou-se ponto mínimo de $205,38 \mathrm{mg} \mathrm{L}^{-1}$ na dose de $10 \mathrm{~kg}$ de esterco independentemente da adubação mineral (Figura 2D).

A fotossíntese liquida, a transpiração, a condutância estomática e a concentração intercelular de $\mathrm{CO}_{2}$ são parâmetros correlacionado e que servem para diagnosticar alterações fisiológicas nas plantas quando submetidas a condições adversas como a baixa e a elevada quantidade de
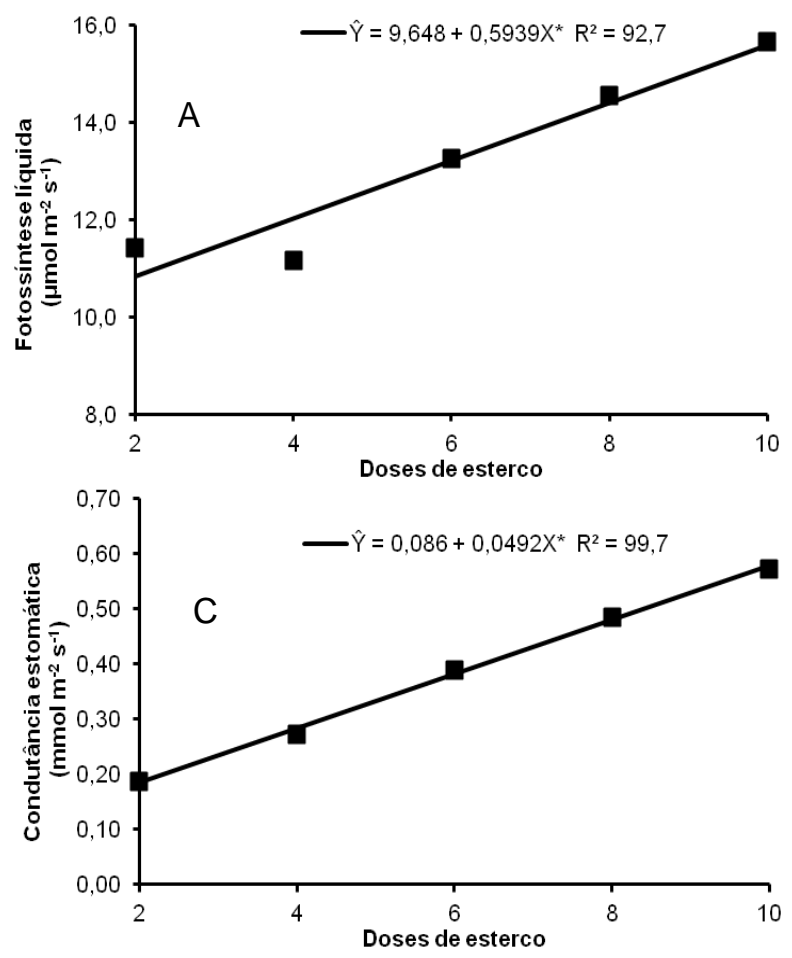

nutrientes. De acordo com Taiz e Zeiger (2004) o suprimento inadequado dos elementos essenciais às plantas causam distúrbios nos processos metabólicos o que resulta em funcionamento anormal das plantas. Fontes \& Guimarães (1999) afirmam que é pouco provável a obtenção de produtividade máxima de qualquer hortaliça sem a adição de matéria orgânica, principalmente em solos com baixo ou médio teor de matéria orgânica.
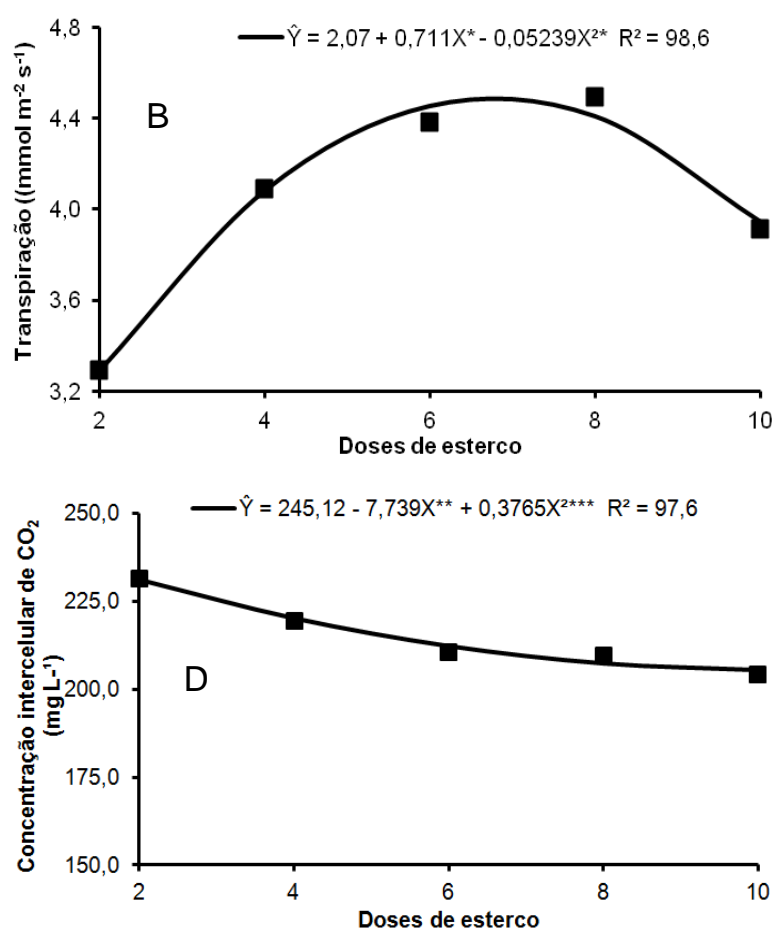

Figura 2. Fotossíntese líquida, transpiração, condutância estomática e concentração intercelular de $\mathrm{CO}_{2}$ em plantas de beterraba submetidas a doses de esterco. UFCG, Pombal, 2014.

\section{CONCLUSÕES}

A aplicação da adubação mineral e a dose de esterco de $6 \mathrm{~kg} \mathrm{~m}^{-2}$ proporcionaram melhor desempenho no crescimento, acúmulo de massa seca e produção da beterraba.

Os valores de fotossíntese líquida, transpiração, condutância estomática e concentração intercelular de $\mathrm{CO}_{2}$ na beterraba foram influenciados pelas doses de esterco.

\section{REFERÊNCIAS BIBLIOGRÁFICAS}

BRANDÃO FILHO, J. U. T.; GOTO, R.; GUIMARÃES, V. F.; HABERMANN, G.; RODRIGUES, J. D.; CALLEGARI, O. Influência da enxertia nas trocas gasosas de dois híbridos de berinjela cultivados em ambiente protegido. Horticultura Brasileira, v. 21, n. 3, p. $474-477,2003$.

CAKMAK, I. The role of potassium in alleviating detrimental effects of abiotic stresses in plants. Journal of Plant Nutrition and Soil Science, v.168, p.521-530, 2005.
CATUCHI, T.A.; GUIDORIZZI, F.V.C.; GUIDORIZI, K.A.; BARBOSA, A.M.; SOUZA, G.M. Respostas fisiológicas de cultivares de soja à adubação potássica sob diferentes regimes hídricos. Pesquisa agropecuária brasileira, Brasília, v.47, n.4, p.519-527, abr. 2012.

COSTA, P. C.; DIDONE, E. B.; SESSO, T. M.; CAÑIZARES, K. A. L.; GOTO, R. Condutividade elétrica de solução nutritiva de alface em hidroponia. Scientia Agricola, v. 58, p. 595-597, 2001.

EPSTEIN, E.; BLOOM, A. J. Nutrição mineral de plantas: princípios e perspectivas. $2^{\circ}$ ed. Londrina: Planta, 2006. 392p.

FONTES, P. C. R.; GUIMARÃES, T. G. Manejo dos fertilizantes nas culturas de hortaliças cultivadas em solo, em ambiente protegido. Informe Agropecuário, v. 20, n. 200/201, p. 36-44, 1999.

LARCHER, W. Ecofisiologia vegetal, São Carlos: Rima artes, 2004. 531 p. 
LAWLOR, D. R. Carbon and nitrogen assimilation in relation to yield: mechanisms are the key to undertanding production sytems. Jounal of Experimental Botany, v. 53, p. 773-787, 2002.

PRADO, R.M. Potássio. In: PRADO, R.M. Nutrição de plantas. São Paulo: UNESP, 2008. p.161-181.

RAIJ, B.V.; CANTARELLA, H.; QUAGGIO, J.A.; FURLANI, A.M.C. Recomendações de adubação e calagem para o Estado de São Paulo. 2.ed. Campinas: Instituto Agronômico/ Fundação IAC. 1997. 285p.

SILVA, F. A. M.; VILLAS BÔAS, R. L. V.; SILVA, R. B. Resposta da alface à adubação nitrogenada com diferentes compostos orgânicos em dois ciclos sucessivos. Acta Scientiarum Agronomy, v. 32, n. 1, p. 131- 137, 2010.
SOUZA, R.J. de.; FONTANETTI, A.; FIORINI, C.V.A.; ALMEIDA, K. de. Cultura da beterraba (Cultivo convencional e Cultivo orgânico). Lavras, 2003, 37p.

TAIZ, L.; ZEIGER, E. Fisiologia Vegetal. Trad. Eliane Romanato Santarém et. al. (3 ed.), Porto Alegre: Artmed, 2004. 719 p.

VILANOVA, C.; SILVA JUNIOR, C. D. Avaliação da trofobiose quanto às respostas ecofisiológicas e bioquímicas de couve e pimentão, sob cultivos orgânico e convencional. Revista Brasileira de Agroecologia, v. 5, n. 1, p. 127-137, 2010.

VILLAS BÔAS, R.L.; PASSOS, J.C.; FERNANDES, M.; BÜLL, L.T.; CEZAR, V.R.S.; GOTO, R. Efeito de doses e tipos de compostos orgânicos na produção de alface em dois solos sob ambiente protegido. Horticultura Brasileira, Brasília, v.22, n.1, p.28-34, jan-mar 2004. 